REVISTA DE DERECHO UNED, NÚM. 9, 2011

\title{
PODER LEGISLATIVO Y SENSIBILIDAD SOCIAL: ALGUNAS APORTACIONES DE LA HISTORIA DEL DERECHO
}

\author{
Matteo Nacci \\ Profesor de Historia del Derecho Canónico \\ Pontificia Universidad Lateranense
}

Resumen: El presente estudio parte de la hipótesis de que, no sólo la teoría general y la filosofía del derecho, sino también la historia del derecho secular y del derecho canónico, puede arrojar alguna luz sobre la peligrosa desafección entre el poder legislativo y la sensibilidad social que caracteriza la época actual. La reflexión se propone presentando el diverso protagonismo que en cada época (medieval, moderna) ha correspondido a la societas y al legislator, con las relativas ambigüedades sobre la relación entre ius y lex. Respecto a la actual coyuntura de globalización jurídica, este estudio concluye proponiendo los criterios de la receptividad social y de la efectividad como vías de solución ante el divorcio entre poder legislativo y sensibilidad social; dichos criterios plantean nuevos retos a la ciencia jurídica, además de resultar base crítica adecuada ante el aislamiento de los poderes legislativos, en sus distintos niveles.

Palabras clave: poder legislativo, sensus fidelium, communitas medieval, individualismo moderno, función creadora del derecho, historia del derecho, globalización, utilidad social, efectividad social.

Abstract: The present work starts from the hypothesis that not only the general theory and philosophy of law, but also the secular and canon history of law can be enlightening for the dangerous gap between legislative power and social sensibility that characterizes the present time. The remarks start introducing the different part of 
societas and legislator in each age (medieval, modern), with the difficulty relationship between ius and lex. In reference to the actual situation of legal globalization, this work proposes the social reception and real actuality criteria as solutions to face the divorce between legislative power and social sensibility; these criteria pose new challenges at legal science and are a consistent critical base against the isolation of legislative power level of expression's.

Key words: legislative power, sensus fidelium, medieval communitas, modern individualism, law creative function's, history of law, globalization, social utility, social reality.

Sumario: I. Introducción. II. La importancia de la utilidad comunitaria de las normas en la experiencia jurídica del ordenamiento canónico. III. El papel central de la communitas y su repercusión en la creación de las normas en la Edad Media. IV. El individualismo y el positivismo de la Edad Moderna y su influjo en el fortalecimiento de la autoridad legislativa. V. Receptividad social y efectividad como criterios de legitimación o rechazo de las normas en la era actual.

\section{INTRODUCCIÓN}

Aunque nunca ha resultado fácil su conjunción, la relación entre el poder legislativo y la sociedad parece atravesar hoy uno de sus momentos más críticos. Esa situación se manifiesta en distintas problemáticas que marcan la actualidad social: la desconfianza en las instituciones, la escasa participación electoral, el rechazo de la llamada "partitocracia», el fallido refrendo popular de algunas leyes relativas a importantes y ambiciosos proyectos internacionales, ... Estas y otras cuestiones semejantes merecen ser objeto de estudio, especialmente desde las ciencias políticas y sociales.

Puede pensarse que, en el caso de la ciencia jurídica, la reflexión sobre los vínculos que deben existir entre la actividad legislativa, en sus distintos niveles, y la sensibilidad social, pertenezca de forma exclusiva a la teoría general o a la filosofía del derecho, entendiendo que dicho problema deba ser integrado, en cuanto derivación concreta, en el tema más amplio concerniente las ideas de Derecho y Justicia, con su relativa expresión en las diversas fuentes normativas ${ }^{1}$.

${ }^{1}$ A la filosofía y teoría general se confía el delicado problema sobre la existencia de valores previa a su inclusión en el ordenamiento jurídico, al que correspondería sólo reconocerlos, no otorgarlos; sobre este punto, cfr. L. Mengoni, Diritto e valori, Bologna 1985, 5 ss. 
Sin embargo, tomando como referencia inmediata el dato negativo, esto es, la peligrosa desafección entre poder legislativo y sociedad, hay otro sector de la ciencia jurídica que puede ofrecer aportaciones enraizadas en la experiencia real, sin menospreciar con ello los contenidos de los citados ramos del saber jurídico, que no por abstractos son menos indispensables. Se trata de la historia del derecho, tanto del derecho secular como del derecho canónico, de la que cabe deducir criterios útiles sobre la legitimación social del poder legislativo.

En concreto, en el presente estudio se intenta iluminar el problema del desarraigo entre derecho positivo y valores sociales desde el papel que, según las principales elaboraciones doctrinales, que han marcado la evolución del pensamiento jurídico, se ha venido asignando tanto a la autoridad legislativa como a la comunidad, en cada época de la historia. Por su utilidad respecto a otros ordenamientos, iniciaremos con una breve referencia a los criterios que rigen desde su origen en el derecho canónico; sucesivamente se mostrarán las oscilaciones entre el mayor peso reconocido a la comunidad, en la Edad Media, o el reconocido de manera casi exclusiva y excluyente, en la experiencia moderna, al poder legislativo; ello consentirá valorar si, desde esas lecciones de la historia, deriva alguna pista útil para la actual coyuntura jurídica en la era postmoderna.

\section{LA IMPORTANCIA DE LA UTILIDAD COMUNITARIA DE LAS NORMAS EN LA EXPERIENCIA JURIDICA DEL ORDENAMIENTO CANONICO}

En cuanto ordenamiento material, el derecho canónico cifra la justificación de sus contenidos especialmente en su coherencia con la experiencia que dio origen a la Iglesia, cuya fijación esencial, a través de reglas jurídicas, resulta ser el sentido último de las normas canónicas. La conciencia de mantener fielmente esa coherencia se manifestó inmediatamente en la vida de la primitiva Iglesia y rigió los esfuerzos por encontrar soluciones y aliviar las tensiones que surgieron, ya incluso en la época de la comunidad apostólica, intentando distinguir lo que se creía elemento constitutivo de la voluntad de Dios sobre la Iglesia (el así llamado «derecho divino»)² de lo que, también

${ }^{2}$ La teología distingue entre el derecho divino en sí, como contenido inmutable, y la capacidad de descifrarlo y traducirlo a categorías jurídicas; esta última está some- 
desde muy pronto, se consideró remitido a la responsabilidad de la misma Iglesia, tras el debido discernimiento ${ }^{3}$.

Ahora bien, esa experiencia originaria está toda ella volcada en la misión evangelizadora; de ahí que, en su dimensión de ordenamiento formal, el principal criterio de justificación del derecho canónico resulta ser la eficacia de sus contendidos respecto a las necesidades de la vida y de la misión de la comunidad. La pluralidad de sus fuentes iniciales (cánones conciliares, decretales de los papas, capitula episcoporum $)^{4}$, y su extensión como derecho universal, explican la variedad de estrategias usadas en la historia de la Iglesia para abordar las inevitables contradicciones entre sus normas; de esa variedad son reflejo los primeros intentos de sistematización elaborados por los precursores de Graciano (Bernoldo di Costanza ${ }^{5}$, Ivo di Chartres ${ }^{6}$, Algero

tida a la evolución histórica; cfr. K. RHANER, Sobre el concepto de Ius divinum en su comprensión católica, en Escritos de teología, V, Madrid 1964, 247-273.

3 Aun en ese tipo de decisiones humanas la primitiva Iglesia no se sintió completamente desligada de su esfuerzo por ser fiel a la voluntad de Dios, expresando los resultados de discernimientos importantes (como fue el relativo a la obligatoriedad o menos de algunas prescripciones de la Thorah para los cristianos provenientes del paganismo) con una fórmula significativa: «hemos decidido el Espíritu Santo y nosotros» (Hech XXX).

4 Sobre las fuentes del derecho canónico véanse, ex multis, A. TARDIF, Histoire des sources du droit canonique, Paris 1887; P. FouRNIER-G. LE BrAs, Histoire des collections canoniques en Occident depuis les fausses décrétales jusqu'au Décret de Gratien, II voll., Paris 1932; B. KurTscheID-F. A. Wilches, Historia iuris canonici, I, Historia fontium et scientiae iuris canonici, Romae 1943; I. A. ZEIGER, Historia iuris canonici, I, De historia fontium et scientiae iuris canonici, Romae 1947; A. M. STICKLER, Historia iuris canonici Latini. Institutiones academicae, I, Historia fontium, Taurini 1950; A. García y García, Historia del derecho canónico, I, El primer milenio, Salamanca 1967; J. Gaudemet, Le sources du droit de l'Église en Occident du II au VII siècle (Initiations au christianisme ancien), s. 1. 1985; ID., Le sources du droit canonique, VIII-XX siècle. Repères canoniques. Sources occidentales (Droit canonique), Paris 1993; B. E. Ferme, Introduzione alla storia delle fonti del diritto canonico, I, Il diritto antico fino al Decretum di Graziano, Mursia 1998; L. KérY, Canonical collections of the early middle ages (ca. 400-1140). A bibliographical guide to the manuscripts and literature (History of medieval canon law, 1), Washington, DC, 2000; G. L. FALCHI-B. E. Ferme, Introduzione allo studio delle fonti dell'utrumque ius, Città del Vaticano 2006; P. ERDÖ, Storia delle Fonti del Diritto Canonico, Venezia 2008.

5 Bernoldus Constantientis, De excommunicatis vitandis, de reconciliatione lapsorum et de fontibus iuris ecclesiastici, en J. P. Migne (a cura di), Patrologia Latina (PL), CXLVIII, coll. 1181-1218; ID., De prudenti dispensatione ecclesiasticarum sanctionum, en Monumenta Germaniae Historica inde ab a.C.500 usque ad a.1500, Leges, Libelli de lite imperatorum et Pontificum, II, 156 ss.

6 Ivo Carnotensis Episcopus, Panormia, Prologus, en PL, CLXI, coll. 47-60. Cfr. J. Werckmeister, Yves de Chartres: Prologue, texte latin et traduction française, Paris 1997; ID., Le premier «canoniste»: Yves de Chartres, en Revue de droit canonique, 47/1 (1997), 53-70. 
di Liegi ${ }^{7}$, Pietro Abelardo ${ }^{8}$ ), las concordancias de Graciano ${ }^{9}$ y las sucesivas codificaciones ${ }^{10}$.

Cualquiera de las mencionadas estrategias seguidas en los diferentes momentos en los que se sintió la necesidad de poner orden en las fuentes del derecho canónico muestra que, entre sus normas, existe un núcleo reducido que se caracteriza por la estabilidad, al que se añade otro núcleo mucho más amplio, caracterizado por la flexibilidad y la adaptación a las necesidades de los fieles y a las exigencias de la misión ${ }^{11}$.

En tal sentido, sin menoscabo de la prioridad que corresponde a los fundamentos teológicos estables del derecho canónico, pero cuyo interés para la reflexión sobre otros sistemas jurídicos es necesariamente más reducido, puede afirmarse que en la historia del derecho de la Iglesia emerge otro criterio esencial, cuya utilidad supera los límites de la regulación jurídica de la comunidad eclesial, mostrándose criterio válido respecto a la eficacia de cualquier ordenamiento. En efecto, la evolución histórica del derecho canónico ofrece un ejemplar testimonio sobre la necesidad de asegurar que el derecho esté al servicio de la vida (ius sequitur vitam). Ello implica que el ejercicio legítimo del poder legislativo no pueda agotarse en su mera correspondencia con la legítima designación del legislador, sino que alcance también la capacidad de resultar un servicio útil a la sociedad destinataria de las leyes.

\section{EL PAPEL CENTRAL DE LA COMMUNITAS Y SU REPERCUSION EN LA CREACION DE LAS NORMAS EN LA EDAD MEDIA}

En las elaboraciones doctrinales surgidas en la Edad Media, tanto dentro como fuera de la Iglesia, se puede afirmar que la comunidad

7 Algerus Leodiensis, De misericordia et iustitia. Cfr. R. Kretzschmar, Alger von Lüttichs Traktat "De misericordia et iustitia», Sigmaringen 1985.

8 Petrus Abaelardus, Sic et non, en PL, CVXXVIII, coll. 1339-1349. Cfr. B. BoyerR. MCKeon, Peter Abailard: Sic et non. A critical edition, Chicago-London 1976-1977.

9 Gratianus, Decretum Magistri Gratiani, en Ae. Friedberg (a cura di), Corpus iuris canonici, Pars prior, ex officina Bernhardi Tauchnitz, Lipsiae MDCCCLXXIX. Sobre Graciano y el Decretum cfr. C. FANTAPPIÈ, Introduzione storica al diritto canonico, Bologna 2003; P. Erdö, Storia delle Fonti del Diritto Canonico, Venezia 2008.

10 Codex Iuris CanonicI, Pii X Pontificis Maximi, iussu digestus Benedicti Papae XV auctoritate promulgatus, en AAS 9 (1917) 11-456; CODEX IURIS CANONICI, auctoritate Ioannis Pauli PP. II promulgatus, en AAS 75 (1983) 1-317; Codex CANONUM ECClesiarum ORIENTALIUM, auctoritate Ioannis Pauli PP. II promulgatus, en AAS 82 (1990) 1033-1363.

11 Sobre los citados criterios de legitimación del derecho canónico, cfr. M. J. Arroba Conde, Diritto processuale canonico, Roma 2006, 27. 
aparece como piedra angular de la organización social y de las ideas sobre la justicia. En ese sentido, la adecuada consideración de la communitas en si misma se revela como eje central sobre el que gira la legitimidad del sistema jurídico, además de ser válvula de control contra el peligro de identificar automáticamente ius y lex. Al mismo tiempo, en esta visión del hombre y de la sociedad, la centralidad de la comunidad ayuda a cifrar la legitimidad del ejercicio del poder, no permitiendo entenderla exclusivamente desde la capacidad de estar al servicio del poder mismo, sino desde el servicio que el poder presta al orden jurídico que reside en la comunidad, cual destinataria final de las leyes.

El papel central de la comunidad como fundamento del ordenamiento jurídico corresponde a la visión antropológica de la época; al respecto resulta emblemática la aportación de Santo Tomás ${ }^{12}$, quien al final del s. XIII representa la summa de la antropología medieval, en la que la relación «unus homo - communitas» se entiende como relación entre «imperfectum - perfectum» ${ }^{13}$.

Por tanto, es la comunidad, en sus diversas manifestaciones, la única protagonista de un entramado cuya naturaleza es al mismo

12 Entre las numerosas obras monográficas sobre la filosofía tomista, cfr. M. Grabmann, San Tommaso. Una introduzione alla sua personalità e al suo pensiero, Milano 1920; O. LotTin, La morale naturel et la loi positive d'après St-Thomas d'Aquin, Lovanio-Bruxelles 1920; O. LotTin, Le droit naturel chez St-Thomas d'Aquin et ses prédecésseurs, Bruges 1931; F. Olgiati, Il concetto di giuridicità in san Tommaso d'Aquino, Milano 1944; A. D. Sertillanges, La philosophie morale de St-Thomas d'Aquin, Paris 1947; C. Giacon, Le grandi tesi del tomismo, Milano 1948; J. E. NAus, The Nature of the Practical Intellect According to St-Thomas d'Aquin, Roma 1959; M. D. CHENU, St-Tomas d'Aquin et la theologie, Paris 1960; L. De Simone, San Tommaso d'Aquino: storia della vita e dell'opera, Napoli 1963; C. Allegro, Il metodo e il pensiero di san Tommaso d'Aquino, Roma 1978; G. ABBA, Lex et virtus: studi sull'evoluzione della dottrina morale di san Tommaso d'Aquino, Roma 1983; M. LA SPISA, San Tommaso e il pensiero post-moderno, Milano 1983; I. BIFf, San Tommaso d'Aquino: il teologo, la teologia, Milano 1992; R. SPIAZzI, Il pensiero di san Tommaso d'Aquino, Bologna 1997; B. Mondin, Dizionario enciclopedico del pensiero di san Tommaso d'Aquino, Bologna 2000; O. DE Bertolis, Il diritto in san Tommaso d'Aquino: un'indagine filosofica, Roma 2000; R. Pizzorni, Diritto, morale, religione: il fondamento etico religioso del diritto secondo san Tommaso d'Aquino, Città del Vaticano 2001; B. Mondin, La metafisica di s. Tommaso d'Aquino e i suoi interpreti, Bologna 2002; J. MARITAIN, Il dottore angelico: San Tommaso d'Aquino, Siena 2006; G. K. Chesterton, San Tommaso d'Aquino, traducción italiana de G. Caputo, Torino 2008.

${ }_{13}$ S. Thomas, Summa Theologice, Secunda Secunda, q. 47, art. 10: «[...] Videtur quod prudentia non se extendat ad regimen multitudinis, sed solum ad regimen sui ipsius. Dicit enim philosophus, in V Ethic., quod virtus relata ad bonum commune est iustitia. Sed prudentia differt a iustitia. Ergo prudentia non refertur ad bonum commune. Praeterea, ille videtur esse prudens qui sibi ipsi bonum quaerit et operatur. Sed frequenter illi qui quaerunt bona communia negligunt sua. Ergo non sunt prudentes. Praeterea, prudentia dividitur contra temperantiam et fortitudinem. Sed temperantia et 


\section{tiempo teológica, política y jurídica ${ }^{14}$. El protagonismo comunitario comporta a su vez que, aun sin negar radicalmente el valor de la persona, en el mismo periodo medieval, no falten manifestaciones de}

fortitudo videntur dici solum per comparationem ad bonum proprium. Ergo etiam et prudentia. Sed contra est quod dominus dicit, Matth. XXIV, quis, putas, est fidelis servus et prudens, quem constituit dominus super familiam suam? Respondeo dicendum quod, sicut philosophus dicit, in VI Ethic., quidam posuerunt quod prudentia non se extendit ad bonum commune, sed solum ad bonum proprium. Et hoc ideo quia existimabant quod non oportet hominem quaerere nisi bonum proprium. Sed haec aestimatio repugnat caritati, quae non quaerit quae sua sunt, ut dicitur I ad Cor. XIII. Unde et apostolus de seipso dicit, I ad Cor. X, non quaerens quod mihi utile sit, sed quod multis, ut salvi fiant. Repugnat etiam rationi rectae, quae hoc iudicat, quod bonum commune sit melius quam bonum unius. Quia igitur ad prudentiam pertinet recte consiliari, iudicare et praecipere de his per quae pervenitur ad debitum finem, manifestum est quod prudentia non solum se habet ad bonum privatum unius hominis, sed etiam ad bonum commune multitudinis. Ad primum ergo dicendum quod philosophus ibi loquitur de virtute morali. Sicut autem omnis virtus moralis relata ad bonum commune dicitur legalis iustitia, ita prudentia relata ad bonum commune vocatur politica, ut sic se habeat politica ad iustitiam legalem, sicut se habet prudentia simpliciter dicta ad virtutem moralem. Ad secundum dicendum quod ille qui quaerit bonum commune multitudinis ex consequenti etiam quaerit bonum suum, propter duo. Primo quidem, quia bonum proprium non potest esse sine bono communi vel familiae vel civitatis aut regni. Unde et maximus Valerius dicit de antiquis Romanis quod malebant esse pauperes in divite imperio quam divites in paupere imperio. Secundo quia, cum homo sit pars domus et civitatis, oportet quod homo consideret quid sit sibi bonum ex hoc quod est prudens circa bonum multitudinis, bona enim dispositio partis accipitur secundum habitudinem ad totum; quia ut Augustinus dicit, in libro Confess., turpis est omnis pars suo toti non congruens. Ad tertium dicendum quod etiam temperantia et fortitudo possunt referri ad bonum commune, unde de actibus earum dantur praecepta legis, ut dicitur in $V$ Ethic. Magis tamen prudentia et iustitia, quae pertinent ad partem rationalem, ad quam directe pertinent communia, sicut ad partem sensitivam pertinent singularia»; cfr. P. GrossI, L'ordine giuridico medievale, Bari 1997, 79-80.

${ }^{14}$ S. Thomas, Summa Theologice, Prima Secunda, q. 90, art. 2: " [...] Videtur quod lex non ordinetur semper ad bonum commune sicut ad finem. Ad legem enim pertinet praecipere et prohibere. Sed praecepta ordinantur ad quaedam singularia bona. Non ergo semper finis legis est bonum commune. Praeterea, lex dirigit hominem ad agendum. Sed actus humani sunt in particularibus. Ergo et lex ad aliquod particulare bonum ordinatur. Praeterea, Isidorus dicit, in libro Etymol., si ratione lex constat, lex erit omne quod ratione constiterit. Sed ratione consistit non solum quod ordinatur ad bonum commune, sed etiam quod ordinatur ad bonum privatum. Ergo lex non ordinatur solum ad bonum commune, sed etiam ad bonum privatum unius. Sed contra est quod Isidorus dicit, in $V$ Etymol., quod lex est nullo privato commodo, sed pro communi utilitate civium conscripta. Respondeo dicendum quod, sicut dictum est, lex pertinet ad id quod est principium humanorum actuum, ex eo quod est regula et mensura. Sicut autem ratio est principium humanorum actuum, ita etiam in ipsa ratione est aliquid quod est principium respectu omnium aliorum. Unde ad hoc oportet quod principaliter et maxime pertineat lex. Primum autem principium in operativis, quorum est ratio practica, est finis ultimus. Est autem ultimus finis humanae vitae felicitas vel beatitudo, ut supra habitum est. Unde oportet quod lex maxime respiciat ordinem qui est in beatitudunem. Rursus, cum omnis pars ordinetur ad totum sicut imperfectum ad perfectum; unus autem 
desconfianza hacia el individuo, tanto hacia el hombre común como hacia el príncipe.

Se trata de una desconfianza que hunde sus raíces en razones de diversa índole, de las que son exponentes otros autores anteriores a Santo Tomás, y cuyas doctrinas fueron provocando la idea de considerar la comunidad como "sujeto colectivo» que encarna la supremacía social, política y jurídica.

En efecto, ya antes del Aquinate, en la especulación teológica y filosófica se encuentra con frecuencia la alusión a la dualidad entre «imperfección de la persona -perfección de la comunidad». Dicha dualidad aparece claramente en San Agustín de Hipona, pensador del siglo V, para el que cada criatura es parte de un tejido de nivel superior, que prescinde de la singularidad y que constituye una realidad perfecta, hermosa, que se materializa en un orden justo igualmente perfecto, en cuanto formado por el conjunto de las personas que voluntariamente renuncian a su individualidad y forman un único cuerpo capaz de ordenarse al bien de la comunidad ${ }^{15}$.

Ulterior elemento importante en el desarrollo del pensamiento teológico y filosófico medieval sobre la supremacía de la communitas

homo est pars communitatis perfectae; necesse est quod lex proprie respiciat ordinem ad felicitatem communem. Unde et philosophus, in praemissa definitione legalium, mentionem facit et de felicitate et communione politica. Dicit enim, in V Ethic., quod legalia iusta dicimus factiva et conservativa felicitatis et particularum ipsius, politica communicatione, perfecta enim communitas civitas est, ut dicitur in I Polit. In quolibet autem genere id quod maxime dicitur, est principium aliorum, et alia dicuntur secundum ordinem ad ipsum, sicut ignis, qui est maxime calidus, est causa caliditatis in corporibus mixtis, quae intantum dicuntur calida, inquantum participant de igne. Unde oportet quod, cum lex maxime dicatur secundum ordinem ad bonum commune, quodcumque aliud praeceptum de particulari opere non habeat rationem legis nisi secundum ordinem ad bonum commune. Et ideo omnis lex ad bonum commune ordinatur. Ad primum ergo dicendum quod praeceptum importat applicationem legis ad ea quae ex lege regulantur. Ordo autem ad bonum commune, qui pertinet ad legem, est applicabilis ad singulares fines. Et secundum hoc, etiam de particularibus quibusdam praecepta dantur. Ad secundum dicendum quod operationes quidem sunt in particularibus, sed illa particularia referri possunt ad bonum commune, non quidem communitate generis vel speciei, sed communitate causae finalis, secundum quod bonum commune dicitur finis communis. Ad tertium dicendum quod, sicut nihil constat firmiter secundum rationem speculativam nisi per resolutionem ad prima principia indemonstrabilia, ita firmiter nihil constat per rationem practicam nisi per ordinationem ad ultimum finem, qui est bonum commune. Quod autem hoc modo ratione constat, legis rationem habet».

15 Aurelius Augustinus Hipponensis, Sancti Aurelii Augustini Enarrationes in psalmos CI-CL (en Corpus christianorum - Series latina, XL, pars X, 3), en psalmum CXLIV, n. 13: "[...] ista contextio creaturae, ista ordinatissima pulchritudo, ab imis ad summa conscendens, a summis ad ima descendens nusquam interrupta sed dissimilibus temperata». 
respecto al unus homo se encuentra en Hugo de San Víctor, quien afirma claramente que el bien y los valores buenos no se manifiestan plenamente en cada uno de los hombres, considerados en su individualidad, sino en un orden jerárquico que constituye la universitas ${ }^{16}$. Para justificar mejor sus argumentos el autor sostiene que la gracia, aunque opera en cada individuo, encuentra su campo de efusión por excelencia sólo en la «unidad compleja», esto es, la que forman las personas que renuncian a su individualidad por el bien común superior. Ello significa que, fuera de esa unidad compleja, el individuo no pueda obtener los beneficios de la gracia, que únicamente despliega su fuerza a favor del individuo en cuanto miembro de la citada «universitas ${ }^{17}$, concepto que acaba imponiéndose y determinando todo el orden jurídico medieval ${ }^{18}$.

En efecto, como consecuencia de los citados rasgos del pensamiento antropológico, también el ordenamiento jurídico medieval, en su complejidad, se impregna de la idea de desconfianza generalizada hacia el individuo, compensada con la convicción, profundamente arraigada, de que sólo la communitas-societas, como conjunto de personas unidas, puede abordar y dominar las situaciones de la vida cotidiana. La Iglesia, como comunidad que vive en medio del mismo mundo al que se siente llamada a evangelizar, participa de los avatares del pensamiento de cada época, y contribuye en gran medida a formar y difundir el mensaje según el cual el individuo, por sí solo, es un ser imperfecto, que necesita de la comunidad para lograr su plena realización. Manifestación sublime de este convencimiento, en su traducción jurídica, es el principio «extra Ecclesia nulla Salus» ${ }^{19}$.

La centralidad otorgada a la comunidad y la concepción antropológica y jurídica de la experiencia medieval comportan a su vez que el papel asignado al titular del poder político resulte circunscrito, especialmente en el ejercicio de la actividad legislativa. De ello da espléndida muestra Santo Tomás de Aquino en su famosa definición de la lex, considerada justamente como la mejor síntesis del

${ }^{16}$ Hugonis de S. Victore, Commentariorum in Hierarchiam coelestem S. Dionysii Areopagitae... libri X, en PL, CLXXV, coll. 1003-1004.

17 Ibidem.

18 El Prof. Paolo Grossi ha explicado en varios escritos la importancia del concepto de imperfección del individuo y de perfección de la comunidad como base del orden jurídico de la Edad Media; cfr. P. GRossi, L'ordine giuridico medievale ...cit.; ID., Società, Diritto, Stato. Un recupero per il diritto, Milano 2006; ID., Modernità politica e ordine giuridico, en Assolutismo giuridico e diritto privato, Milano 1998, 443-469.

19 Sobre este asunto cfr. P. Grossi, L'ordine giuridico medievale ...cit., 109-116. 
pensamiento jurídico de la Edad Media: «quaedam rationis ordinatio ad bonum commune, ab eo qui curam communitatis habet, promul-

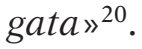

El Doctor angelicus indica el importante papel que corresponde a la comunidad al afirmar que la ley se dirige «ad bonum commune», una expresión de alto valor finalístico, cuya carencia provocaría la invalidez de la norma jurídica. En tal visión, el papel de quien gobierna la comunidad resulta limitado, asignando a sus poderes una función de naturaleza más bien declarativa, por lo que, como consecuencia lógica, son muy limitados los aspectos o componentes propiamente voluntaristas, hasta el punto que no parece incluirse la existencia de una función completamente creativa en el legislador.

Santo Tomás, para subrayar con mayor claridad el papel más bien «ordenador» que corresponde al detentador del poder, reclama en varias ocasiones el instrumentum ordinationis, esto es, la razón. Ello significa que la ordenación que corresponde al legislador, en cuanto operación racional, es una actividad principalmente cognoscitiva, por lo que quien detenta el poder debiera moverse con una profundad humildad, con absoluto respeto y denodado afán por descifrar los datos normativos ya inscritos en la naturaleza de las cosas y

20 S. Thomas, Summa Theologice, Prima Secunda, q. 90, art. 4: «[...] Videtur quod promulgatio non sit de ratione legis. Lex enim naturalis maxime habet rationem legis. Sed lex naturalis non indiget promulgatione. Ergo non est de ratione legis quod promulgetur. Praeterea, ad legem pertinet proprie obligare ad aliquid faciendum vel non faciendum. Sed non solum obligantur ad implendam legem illi coram quibus promulgatur lex, sed etiam alii. Ergo promulgatio non est de ratione legis. Praeterea, obligatio legis extenditur etiam in futurum, quia leges futuris negotiis necessitatem imponunt, ut iura dicunt. Sed promulgatio fit ad praesentes. Ergo promulgatio non est de necessitate legis. Sed contra est quod dicitur in decretis, IV dist., quod leges instituuntur cum promulgantur. Respondeo dicendum quod, sicut dictum est, lex imponitur aliis per modum regulae et mensurae. Regula autem et mensura imponitur per hoc quod applicatur his quae regulantur et mensurantur. Unde ad hoc quod lex virtutem obligandi obtineat, quod est proprium legis, oportet quod applicetur hominibus qui secundum eam regulari debent. Talis autem applicatio fit per hoc quod in notitiam eorum deducitur ex ipsa promulgatione. Unde promulgatio necessaria est ad hoc quod lex habeat suam virtutem. Et sic ex quatuor praedictis potest colligi definitio legis, quae nihil est aliud quam quaedam rationis ordinatio ad bonum commune, ab eo qui curam communitatis habet, promulgata. Ad primum ergo dicendum quod promulgatio legis naturae est ex hoc ipso quod Deus eam mentibus hominum inseruit naturaliter cognoscendam. Ad secundum dicendum quod illi coram quibus lex non promulgatur, obligantur ad legem servandam, inquantum in eorum notitiam devenit per alios, vel devenire potest, promulgatione facta. Ad tertium dicendum quod promulgatio praesens in futurum extenditur per firmitatem Scripturae, quae quodammodo semper eam promulgat. Unde Isidorus dicit, in II Etymol., quod lex a legendo vocata est, quia scripta est». 
en la sociedad. Esta, en cuanto usufructuaria de dichos datos, ya los asume y se rige por ellos, aun antes de que se conviertan en norma jurídica formal ${ }^{21}$.

21 S. Thomas, Summa Theologice, Prima Secundœ, q. 90, art. 1: «[...] Videtur quod lex non sit aliquid rationis. Dicit enim apostolus, ad Rom. VII, video aliam legem in membris meis, et cetera. Sed nihil quod est rationis, est in membris, quia ratio non utitur organo corporali. Ergo lex non est aliquid rationis. Praeterea, in ratione non est nisi potentia, habitus et actus. Sed lex non est ipsa potentia rationis. Similiter etiam non est aliquis habitus rationis, quia habitus rationis sunt virtutes intellectuales, de quibus supra dictum est. Nec etiam est actus rationis, quia cessante rationis actu, lex cessaret, puta in dormientibus. Ergo lex non est aliquid rationis. Praeterea, lex movet eos qui subiiciuntur legi, ad recte agendum. Sed movere ad agendum proprie pertinet ad voluntatem, ut patet ex praemissis. Ergo lex non pertinet ad rationem, sed magis ad voluntatem, secundum quod etiam iurisperitus dicit, quod placuit principi, legis habet vigorem. Sed contra est quod ad legem pertinet praecipere et prohibere. Sed imperare est rationis, ut supra habitum est. Ergo lex est aliquid rationis [...]»; Ivi, q. 91, art. 2: «[...] Videtur quod non sit in nobis aliqua lex naturalis. Sufficienter enim homo gubernatur per legem aeternam, dicit enim Augustinus, in I de Lib. Arb., quod lex aeterna est qua iustum est ut omnia sint ordinatissima. Sed natura non abundat in superfluis, sicut nec deficit in necessariis. Ergo non est aliqua lex homini naturalis. Praeterea, per legem ordinatur homo in suis actibus ad finem, ut supra habitum est. Sed ordinatio humanorum actuum ad finem non est per naturam, sicut accidit in creaturis irrationabilibus, quae solo appetitu naturali agunt propter finem, sed agit homo propter finem per rationem et voluntatem. Ergo non est aliqua lex homini naturalis. Praeterea, quanto aliquis est liberior, tanto minus est sub lege. Sed homo est liberior omnibus animalibus, propter liberum arbitrium, quod prae aliis animalibus habet. Cum igitur alia animalia non subdantur legi naturali, nec homo alicui legi naturali subditur. Sed contra est quod, Rom. II, super illud, cum gentes, quae legem non habent, naturaliter ea quae legis sunt faciunt, dicit Glossa, etsi non habent legem scriptam, habent tamen legem naturalem, qua quilibet intelligit et sibi conscius est quid sit bonum et quid malum. Respondeo dicendum quod, sicut supra dictum est, lex, cum sit regula et mensura, dupliciter potest esse in aliquo, uno modo, sicut in regulante et mensurante; alio modo, sicut in regulato et mensurato, quia inquantum participat aliquid de regula vel mensura, sic regulatur vel mensuratur. Unde cum omnia quae divinae providentiae subduntur, a lege aeterna regulentur et mensurentur, ut ex dictis patet; manifestum est quod omnia participant aliqualiter legem aeternam, inquantum scilicet ex impressione eius habent inclinationes in proprios actus et fines. Inter cetera autem rationalis creatura excellentiori quodam modo divinae providentiae subiacet, inquantum et ipsa fit providentiae particeps, sibi ipsi et aliis providens. Unde et in ipsa participatur ratio aeterna, per quam habet naturalem inclinationem ad debitum actum et finem. Et talis participatio legis aeternae in rationali creatura lex naturalis dicitur. Unde cum Psalmista dixisset, sacrificate sacrificium iustitiae, quasi quibusdam quaerentibus quae sunt iustitiae opera, subiungit, multi dicunt, quis ostendit nobis bona? Cui quaestioni respondens, dicit, signatum est super nos lumen vultus tui, domine, quasi lumen rationis naturalis, quo discernimus quid sit bonum et malum, quod pertinet ad naturalem legem, nihil aliud sit quam impressio divini luminis in nobis. Unde patet quod lex naturalis nihil aliud est quam participatio legis aeternae in rationali creatura. Ad primum ergo dicendum quod ratio illa procederet, si lex naturalis esset aliquid diversum a lege aeterna. Non autem est nisi quaedam participatio eius, ut dictum est. Ad secundum dicendum quod omnis operatio, rationis et voluntatis derivatur in nobis ab eo quod est secundum naturam, ut supra habitum est, nam omnis ratiocinatio derivatur a 
La citada concepción de la ley, ajena a la voluntas principis, en lo que concierne a su creación, se encuentra ya en el pensamiento de Alberto Magno, maestro de Santo Tomás, que hacia la mitad del s. XIII describía la lex como una realidad compleja, en cuya formación concurren tres sujetos: uno determinante, el populus, que la acepta desempeñando una función activa, y la observa en cuanto promulgada para su utilidad; el iurisconsultus, que redacta la ley tras haberla individuado, mediante técnicas jurídicas adecuadas; el princeps, cuya función consiste sólo en dotarla de autoridad formal ${ }^{22}$. En ese sentido, para San Alberto Magno, en la actividad legislativa el papel que se asigna a quien detenta el poder es modesto, al ser la suya una función también modesta, porque externa al proceso de formación de la ley misma. Al contrario, la comunidad y los exponentes de la ciencia jurídica resultan plenamente insertos en dicho proceso.

Como conclusión de las referidas elaboraciones doctrinales, encabezadas por las de Santo Tomás, pueden resumirse en tres los rasgos principales de la experiencia jurídica medieval, cuya suerte resultará alterada radicalmente en la sucesiva experiencia jurídica de la época moderna.

principiis naturaliter notis, et omnis appetitus eorum quae sunt ad finem, derivatur a naturali appetitu ultimi finis. Et sic etiam oportet quod prima directio actuum nostrorum ad finem, fiat per legem naturalem. Ad tertium dicendum quod etiam animalia irrationalia participant rationem aeternam suo modo, sicut et rationalis creatura. Sed quia rationalis creatura participat eam intellectualiter et rationaliter, ideo participatio legis aeternae in creatura rationali proprie lex vocatur, nam lex est aliquid rationis, ut supra dictum est. In creatura autem irrationali non participatur rationaliter, unde non potest dici lex nisi per similitudinem»; Ivi, q. 91, art. 3: "[...] Videtur quod non sit aliqua lex humana. Lex enim naturalis est participatio legis aeternae, ut dictum est. Sed per legem aeternam omnia sunt ordinatissima, ut Augustinus dicit, in I de Lib. Arb. Ergo lex naturalis sufficit ad omnia humana ordinanda. Non est ergo necessarium quod sit aliqua lex humana. Praeterea, lex habet rationem mensurae, ut dictum est. Sed ratio humana non est mensura rerum, sed potius e converso, ut in X Metaphys. dicitur. Ergo ex ratione humana nulla lex procedere potest. Praeterea, mensura debet esse certissima, ut dicitur in X Metaphys. Sed dictamen humanae rationis de rebus gerendis est incertum; secundum illud Sap. IX, cogitationes mortalium timidae, et incertae providentiae nostrae. Ergo ex ratione humana nulla lex procedere potest. Sed contra est quod Augustinus, in I de Lib. Arb., ponit duas leges, unam aeternam et aliam temporalem, quam dicit esse humanam. Respondeo dicendum quod, sicut supra dictum est, lex est quoddam dictamen practicae rationis $[\ldots]$...

22 Albertus Magnus, De bono, en H. Kühle, C. Feckes, B. Geyer, W. KüBel (a cura di), Sancti doctoris Ecclesiae Alberti Magni ordinis fratrum praedicatorum episcopi Opera omnia, Monasterii Westfalorum 1951, Tom. XXVIII, Tract. V, de justitia, q. II, de legibus, art. I, quid sit lex: "lex est constitutio populi per consensum et utilitatem et observationem, iuriconsulti autem est per inventionem et ordinationem, et principis per auctoritatis sanctionem». 
El primer rasgo lo constituye la carencia de proyecto totalizante por parte del poder político, que no pretende tampoco controlar la vida social a través de la ley como instrumento de dominio ${ }^{23}$; el papel de quien detenta el poder político no es el de crear la ley sino el de interpretar los hechos sociales que se encuentran cotidianamente bajo su mirada y, en relación a los cuales, se le emplaza a utilizar con habilidad las lentes de la iurisdictio, entendiéndola como un modus operandi mediante el cual descifrar los comportamientos sociales dignos de tutela y necesitados de reglamentación ${ }^{24}$.

En segundo lugar, la desconfianza en el individuo es proporcional al valor que se reconoce a la comunidad. En tal sentido, sin temor a exagerar, puede hablarse de una mens medieval contraria al individualismo, que mira con recelo al sujeto considerado en sí mismo, aun asignándole gran importancia en cuanto parte integrante del tejido social; un tejido que, aunque protege a cada sujeto, termina siendo el único elemento integral digno de consideración.

Por último, consecuencia lógica de que no haya confusión automática entre ius y lex es el hecho de reconocer que el ius pueda estar también contenido en la conducta repetida por la sociedad, esto es, en la costumbre. Ello significa que el derecho pertenece a la sociedad antes que al poder político encargado de legislar, en cuanto por derecho se entiende el conjunto de datos inscritos en la naturaleza de las cosas, que constituyen las mores y las consuetudines, en las que residen los datos de base imprescindibles a los que el poder legislativo debe adecuarse en su función de promulgar formalmente las normas.

${ }^{23}$ Es importante señalar que en muchos países monárquicos de la Europa medieval (Francia, Portugal, España) son excepcionales, cuando no completamente inexistentes, las intervenciones directas de los detentores del poder político; sobre este particular, cfr. P. Grossi, L'ordine giuridico medievale...cit., 130-135.

${ }^{24}$ Ejemplo significativo de la función «ordenadora» y no "creativa» asignada al detentor del poder político es la Lex Visigothorum, o Liber iudiciorum, del 654 d. C., en la que el rey Recesvinto se limita a recoger las mores ya existentes y procedentes de la visa social del reino de los visigodos, revistiéndolas de los elementos necesarios para convertirse en normas jurídicas formales. Opinión contraria mantiene A. IGLESIA FERREIRÓs, La creación del derecho. Una historia de la formaciòn de un derecho estatal español, vol. I, Barcelona 1992, 225, que considera al «monarca como creador del derecho». Sin embargo, la naturaleza meramente «ordenadora» de la función del rey queda reflejada en la identificación de la citada lex como "anima totius corporis popularis», en cuanto "boni mores inveniens adque componens" (Monumenta Germaniae Historica inde ab a.C.500 usque ad a.1500, Leges nationum germanicarum, vol. I, lib. I, tit. II, De lege, § II, Quid sit lex). 


\section{EL INDIVIDUALISMO Y EL POSITIVISMO DE LA EDAD MODERNA Y SU INFLUJO EN EL FORTALECIMIENTO DE LA AUTORIDAD LEGISLATIVA}

El ordenamiento jurídico medieval cambia a partir del siglo XIV, con el comienzo progresivo de la exaltación del individuo frente a los condicionamientos sociales; dicha modificación en el pensamiento y en la antropología comporta, en la esfera jurídica, una variación importante de acentos, dando paso al moderno individualismo que se refleja en las ideas y en la organización sociopolítica. Los nuevos planteamientos llevaron consigo, respecto a la creación de las leyes, que la sociedad dejase de revestir el papel preponderante que cubría hasta entonces, para asignarlo al poder legislativo, cuya función supera el ámbito modesto, de naturaleza cognoscitiva, que había jugado en la época medieval.

Desde el punto de vista antropológico se asiste a una verdadera revolución de alcance estructural: la exaltación del individuo en cuanto tal, reconociéndole como ser libre, portador de voluntad propia y capaz de establecer relaciones sin necesidad de someterse al filtro condicionante de la communitas, llevó aparejada la destrucción violenta de muchas atribuciones que, hasta entonces, se reconocían solo a las diversas estructuras e instituciones sociales; al mismo tiempo, junto a los logros anexos a las libertades individuales, esta revolución estructural, en detrimento del papel de la sociedad, deja a los individuos sumidos en el riesgo de la soledad y de la incapacidad de reconocer la diversidad que corresponde a otros seres, en cuanto diversos de sí mismo ${ }^{25}$.

Como ocurrió con la centralidad de la sociedad en la época medieval, también la centralidad del individuo en la época moderna es fruto de la reflexión teológica y filosófica del s. XIV, que empieza a abandonar el modelo aristotélico y tomista para asumir planteamientos de cariz antropocéntrico. En ellos se percibe el objetivo de liberar al hombre de incrustaciones acumuladas anteriormente y consideradas inmutables, pero que terminaban siendo sólo un freno indebido a las posibilidades que encierran el esfuerzo y la creatividad humanas.

Con la caída del precedente paradigma filosófico y teológico se derrumbó también su pilar fundamental, esto es, la construcción armónica de las relaciones y del conocimiento humano según el esquema tripartito Dios-hombre-naturaleza. La aportación del movimiento y

${ }^{25}$ Cfr. R. Fisichella, Derechos humanos y ley natural, en Derechos humanos en Europa, Salamanca 2009, 215 ss. 
espiritualidad de los franciscanos resulta muy significativa en la producción de este cambio de perspectiva; dicho pensamiento se asienta, como elemento principal, en reconocer la relación entre Dios y el hombre como la única que cuenta, dejando a parte la naturaleza, en el sentido de que la dignidad de la creación se entiende desde su sometimiento al servicio del hombre, y no viceversa ${ }^{26}$.

En esta nueva visión, prescindir de los vínculos presuntamente derivados de la naturaleza responde al deseo de acrecentar el nivel de autodeterminación de cada hombre, según su voluntad, única facultad capaz de dominar el mundo externo y de garantizar la condición libre que dignifica al ser humano; de ese modo se va formando la idea de que un individuo puede considerarse libre en la medida en que sea capaz, a través de su voluntas, de poner en juego una efectiva y eficaz potestas dominandi sobre todo aquello que le circunda como algo distinto de sí mismo ${ }^{27}$.

Este proceso que, desde las ideas, promueve de centralidad del individuo, tiene una incidencia análoga en las dimensiones política y jurídica, aspectos que merecen ser tratados de forma unitaria. El nuevo panorama, donde el individuo debe actuar por sí mismo y para sí mismo, sin condicionamientos derivados de la naturaleza y de la communitas, era caldo de cultivo adecuado para que surgiese un nuevo sujeto político, el príncipe, capaz de proyectar en su actividad social su voluntad personal, a la que se atribuye en sí misma la perfección necesaria respecto a la capacidad organizativa y de gobierno, sin necesidad de relacionarse con la sociedad misma, verificándose más bien la incapacidad del príncipe para relacionarse con la comunidad. La traducción jurídica de este nuevo modelo, y de su mito del individuo, es la lucha del príncipe, cual titular del poder legislativo, por destruir el pluralismo social y jurídico, y por apropiarse del derecho, haciendo de él un instrumento de gobierno, confundiendo el ius con la lex y convirtiendo su poder en una "piussance absolu et perpétuel», como sostuvo Jean Bodin, al final del s. XVI, en sus Six livres de la Republique ${ }^{28}$.

${ }^{26}$ Cfr. M. Villey, La formation de la pensée juridique moderne, Paris 1968, 147 ss.

27 Un primer ejemplo de los nuevos planteamientos filosóficos y teológicos sobre la centralidad del individuo y su conquista de una posición de dominio en relación al mundo externo se encuentra en el franciscano Pierre de Jean-Olieu que hacia la mitad del s. XIII llega a afirmar que la personalidad de cada hombre es «existentia dominativa et libera et in se ipsam possessiva reflexa vel flexibilis» (PIETRo DI GIOvanNI Olivi, Quaestiones in secundum librum Sententiarum, quas primum ad finem codicum edidit, Quaracchi 1922-1926, II, q. 52, 200).

28 J. Bodin, Le six livres de la Republique, Aalen 1977, 122. 
Es en Francia donde inicia el proceso que llevó a considerar la función del príncipe, en la formulación de las leyes, como una función creadora, que consiente al poder legislativo construir un derecho a su imagen y semejanza, y convertirlo en instrumento de gobierno. La producción de normas autoritarias por parte de la monarquía francesa va acompañada de un cambio radical en la doctrina sobre la ley. En efecto, Michel de Montaigne llega a afirmar que la ley debe ser obedecida no por ser justa o racional -como se afirmaba en la doctrina medieval- sino solo por ser ley, esto es, por provenir del poder legislativo, calificando dicha proveniencia como «le fondement mystique» de la ley misma. Quiere ello decir que el deber de obediencia que merecen las normas jurídicas nada tiene que ver con su contenido; esta idea manifiesta hasta qué punto la evolución de la era moderna llegó a ponerse en las antípodas del pensamiento medie$\mathrm{val}^{29}$.

No es una casualidad que surgiera en Francia esta transformación del planteamiento jurídico medieval; el suelo francés era terreno fértil en el que, durante un largo periodo de tiempo (desde el s. XIV a la Revolución francesa) el soberano, a través de la ordonnance, había empezado a cortar de raíz el complejo entramado jurídico, que se expresaba de forma especial en la coutume; ese cambio progresivo fue acompañado por la supresión de las comunidades intermedias, que el soberano elimina con la idea de realizar la igualdad, confiriendo a cada sujeto una libertad sometida exclusivamente a su voluntad ${ }^{30}$.

29 M. DE Montaigne, Essais, Paris 1836, livre III, chap. XIII: "les loix se maintiennent en credit, non par ce qu'elles sont justes, mais par ce qu'elles sont loix. C'est le fondement mystique des leurs authorité; ells n'en ont point d'autre. Qui bien leur sert. Elles sont souvent faictes par des sots...».

30 Aunque hayamos indicado Francia como paradigma del cambio de la época medieval a la moderna, las ideas sobre la libertad y autonomía del individuo se manifiestan también en autores de otras geografías; entre éstos destaca el pensador inglés Hobbes que en su obra de filosofía política (Leviathan, or the Matter, Form and Power of a Commonwealth Ecclesiastical and Civil), afirma que "un uomo libero è colui che, in quelle cose che con la sua forza e il suo ingegno è in grado di fare, non viene ostacolato nel fare quanto ha la volontà di fare» (T. HobBES, Leviatano, traducción italiana de G. Micheli, Firenze 1976, cap. XXI, 205-206); sobre la obra de Hobbes cf., G. TARANTINO, Saggio sulle idee morali e politiche di Thomas Hobbes, Napoli 1900; L. STRAuss, The Political Philosophy of Hobbes, Oxford 1936; R. Polin, Politique et philosophie chez. Thomas Hobbes, Paris 1952; M. Corsi, Introduzione al Leviatano, Napoli 1967; T. Magri, Saggio su Thomas Hobbes. Gli elementi della politica, Milano 1982; D. NeRI, Teoria della scienza e forma della politica in Thomas Hobbes, Napoli 1984; L. FoISNEAU-G. Wright, Nuove prospettive critiche sul Leviatano di Hobbes, Milano 2004; N. BobBio, Thomas Hobbes, Torino 2004; S. Scorsi, Thomas Hobbes tra giusnaturalismo e positivismo giuridico, Viterbo 2007; G. M. CHIODI-R. GATTI (a cura di), La filosofia politica di Hobbes, Milano 2009. 
Esta revolución estructural, que modificó definitivamente el ordenamiento jurídico medieval, aun siendo la inspiración inicial de las sucesivas orientaciones antropocéntricas y de la conquista de valores que hoy consideramos intocables en la conciencia colectiva (como la dignidad de toda persona y la igualdad ante la ley), provocó sin embargo, de forma irremediable, una ambigüedad de alcance histórico, que se sitúa en un acontecimiento histórico preciso.

Se trata de la Revolución francesa ${ }^{31}$ que constituye la síntesis perfecta de la divinización del positivismo jurídico. La conversión del derecho en normas positivas obedece al deseo de precisión, postulado que resulta aceptable desde el punto de vista formal, pero que se revela profundamente equivocado desde el punto de vista de los contenidos jurídicos, en cuanto termina por unir el derecho al ejercicio del poder legislativo, convirtiendo la ley en la única fuente capaz de expresar, de forma adecuada, la voluntad general sobre las relaciones justas.

Esa ambigüedad histórica produce una diferencia decisiva entre las nociones de lex de la época medieval y la loy moderna: si la primera obedecía a la necesidad de precisión en contenidos (ordenación racional) y fines (para el bien común), la segunda se prospecta como una realidad que no necesita recurrir a la relevancia de sus contenidos y finalidades para obtener legitimación social.

Puede comprenderse pues cómo la edad moderna signifique, respecto al tema que nos ocupa, la mortificación del peso de la sociedad y del pluralismo jurídico, provocando al contrario la exaltación del monismo y del poder político; éste se identifica a su vez con el Estado, al que se asigna toda soberanía, dando paso a la eliminación radical de las comunidades intermedias y de toda su carga de normas consuetudinarias y prácticas peculiares arraigadas. El Estado opera a través de la ley, que resulta ser la longa manus de su estructura totalizante y unificadora, y que conlleva la elaboración de contenidos jurídicos caracterizados por la abstracción, la rigidez y la obligatoriedad siempre incuestionable.

31 Sobre la Revolución francesa cfr. T. CARLYLE, The French Revolution, 3 voll., London 1837; L. Blanc, Historie de la Révolution française, 12 voll. Paris 1847-1862; A. Aulard, Histoire politique de la Révolution, Paris 1901; P. SAGnac, La Révolution, 1789-92, Paris 1920; J. Thompson, The French Revolution, Oxford 1944; L. LefEBVRE, Études sur la Révolution française, Paris 1954; M. Vovelle (a cura di), Les images de la révolution française, Paris 1988; L. Hunt, La Rivoluzione francese. Politica, cultura, classi sociali, Bologna 2007; M. DI CARLO ALBERTo, La Rivoluzione francese. Una rivoluzione da completare, Viterbo 2009. 
Todo ello comporta que la ley se convierta en norma cuya autoridad real sufre el riesgo de resultar exclusivamente formal, pues su legitimación prescinde de considerar los contenidos y se confunde con la legitimación de la autoridad de la que procede, esto es, del legislator, titular exclusivo del poder legislativo. El Estado y el individuo, aunque nuevos y únicos protagonistas del escenario de este periodo histórico, son resultado inevitable del laboratorio jurídico del periodo precedente, esto es, del llamado "proyecto iusnaturalistico» ${ }^{32}$, en el que se forja la idea de liberarse de los condicionamientos medievales vigentes hasta finales del s. $\mathrm{XVI}^{33}$ y de sacudirse los excesivos vínculos generados por la praxis de las corporaciones.

La experiencia jurídica de la Iglesia, obligada a encarnarse en el mundo y a participar de sus vicisitudes, no queda al margen de los cambios estructurales de los ordenamientos jurídicos. Un signo de acomodación a la evolución de la mayoría de los sistemas jurídicos fue la obra de codificación ${ }^{34}$, que unificó el derecho de la Iglesia en

32 La expresión "progetto giusnaturalistico» es del Prof. Paolo Grossi que la explica diciendo que se trata de un proyecto y de una strategia: «un progetto - perché dell'impresa progettuale serba il carattere indubbio di struttura pensatissima -, ma anche una strategia - perché non nasconde la sua tensione a irretire la concretezza della vita quotidiana e a farsi prassi; progetto e strategia che si presentano agli occhi dello storico del diritto soprattutto nell'aspetto di un tentativo - ammirevole nella sua perspicuità - di identificare storia, società, istituzioni come artifici opprimenti e di cominciare a costruire più in là, in un terreno sgombro da ipoteche, dove l'individuo privato e l'individuo politico si potessero finalmente stagliare nella loro netta individualità. Il programma sembrava essere: astrarre e semplificare; lo strumento: una massiccia destoricizzazione e, conseguentemente, desocializzazione; il risultato: un palcoscenico storico ridotto a due sole individuazioni forti [...] l'individuo solitario e lo Stato», P. Grossi, Modernità politica e ordine giuridico...cit., 31-32. Sobre el iusnaturalismo cfr. L. STRAuSs, Diritto naturale e storia, Venezia 1957; G. Solari, La dottrina del diritto naturale nelle dottrine etico-giuridiche dei secoli XVII e XVIII, Torino 1904; H. Welzel, Naturrecht und materiale Gerechtigkeit, Gottinga 1951; E. Di RoBILANT, Significato del diritto naturale nell'ordinamento canonico, Torino 1954; E. Galán y GutiÉRrez, Ius naturae, 2 voll., Madrid 1961; N. BobBio, Giusnaturalismo e Positivismo giuridico, Milano 1972; A. BRIMo, Les grands courants de la philosophie du droit et de l'État, Parigi 1967; A. PASSERIN D'EnTRÈves, La dottrina del diritto naturale, Milano 1980.

${ }_{33}$ Cfr. P. Grossi, Modernità politica e ordine giuridico ... cit., 36-39.

${ }^{34}$ No podemos detenernos en profundidad en el tema complejo del proceso de codificación del derecho de la Iglesia; nos limitamos a señalar algunos de los muchos estudios existentes sobre ello; sobre el CIC 1917 cfr. P. VAN DE KAMP, Codex juris canonici, en Dictionnaire de droit canonique, II, Paris 1909, 909 ss.; A. M. STICKLER, Historia juris canonici latini. Institutiones academicae, I, Historia fontium. (pontificium athenaeum salesianum. Facultas iuri canonici), Torino 1950; C. FANTAPPIE, Chiesa romana e modernità giuridica, tomo II, Il codex iuris canonici (1917), Milano 2008. Sobre el CIC 1983, S. Berlingò, Diritto canonico, Torino 1995, 117-120; P. Moneta, Introduzione al diritto canonico, Torino 2001, 63-67; G. Feliciani, Le basi del diritto canonico, 
un texto normativo único, que ordenaba y recogía, con las menores incoherencias posibles, las normas del Corpus Iuris Canonici vigentes hasta entonces. Aun sin caer en el positivismo jurídico, la codificación significaba hacer depender la legitimación más inmediata de las normas, y su obligatoriedad más segura, del mismo mecanismo utilizado en los Estados modernos, esto es, de su promulgación por parte de la autoridad legislativa. Aun así, la codificación del derecho canónico no ha significado la desaparición del papel reconocido a la comunidad eclesial como sujeto al que también pertenece la función de otorgar legitimidad a las normas. Dicha función se refleja, no solo en instituciones jurídicas internas al mismo ordenamiento canónico, sino también en la conducta crítica promovida por la Iglesia frente a algunas leyes surgidas en el seno de otros ordenamientos jurídicos.

\section{RECEPTIVIDAD SOCIAL Y EFECTIVIDAD COMO CRITERIO DE LEGITIMACIÓN O RECHAZO DE LAS NORMAS EN LA ERA ACTUAL}

Si por legitimación se entiende la fijación formal, en el ordenamiento jurídico, de una praxis utilizada en la gestión de relaciones sociales relevantes, puede afirmarse que, tras las referidas oscilaciones históricas, en la era actual, tanto el derecho de la Iglesia como el de la sociedad global, ofrecen nuevas pistas sobre el equilibrio entre el protagonismo que corresponde al poder legislativo y a la sociedad. En esta fase, aún por delinear en su integridad, el criterio principal que se va imponiendo es el de la receptividad social de las normas, según su efectividad, esto es, su utilidad y aplicabilidad en la vida concreta.

\footnotetext{
Bologna 2002, 38-44; C. FANTAPPIÈ, Introduzione storica al diritto canonico, Bologna 2003, 261-269; L. MusselLI, Storia del diritto canonico. Introduzione allo studio del diritto e delle istituzioni ecclesiali, Torino 2007, 107-115. Sobre el Codex Canonum Ecclesiarum Orientalium, A. Coussa, De codificatione canonica orientali, en AA.VV., Acta Congressus Iuridici Internationalis VII saeculo a Decretalibus Gregorii IX et XIV a Codice Iustiniano promulgatis, IV, Romae 1937, 491-532; D. FALTIN, La codificazione del diritto canonico orientale, en AA.VV., La Sacra Congregazione per le Chiese Orientali nel cinquantesimo della fondazione (1917-1967), Roma 1969, 121-137; D. SALACHAS, Istituzioni di Diritto canonico delle Chiese orientali cattoliche, Bologna 1993, 45-54; J. FARIS, La storia della codificazione orientale, in K. BHARANIKULANGARA (a cura di), Il Diritto Canonico Orientale nell'ordinamento ecclesiale, Città del Vaticano 1995, 255-268; D. SALACHAS-L. SABBARESE, Codificazione latina e orientale e canoni preliminari, Città del Vaticano 2003.
} 
En esta clave, la experiencia más significativa que ofrece la historia del derecho canónico está constituida por la costumbre ${ }^{35}$, incluida la costumbre contra legem, cuya supervivencia a la primera codificación demuestra cuánto se consideraba esencial la función de la comunidad como creadora del derecho ${ }^{36}$. En el surgimiento de una costumbre es a la communitas a quien se reconoce el animus de convertir un comportamiento de hecho en vínculo jurídico.

Al mismo tiempo, la constatación de la caída en desuso de reglas vigentes desde un punto de vista formal, pero no aplicadas de hecho, tal vez por no corresponder a las necesidades de la comunidad misma, fue uno de los criterios expresamente enunciados para guiar la obra de revisión del primer Código de derecho canónico latino (CIC 1917) y de los varios motu proprio que precedieron la promulgación del Codex Canonum Ecclesiarum Orientalium (CCEO 1990).

Respecto a la falta de legitimidad de leyes ajenas al derecho eclesial, independientemente de su inserción formalmente válida en un ordenamiento jurídico a través de la promulgación por parte del po-

35 Entre los estudios sobre la canonica consuetudo cfr. A. FonTANA, Il valore della consuetudine e i suoi requisiti secondo il diritto canonico, Modena, 1907; F. Flumene, La consuetudine nel suo valore giuridico, Sassari 1925; M. CONTE a Coronata, Institutiones iuris canonici, Torino 1928; R. WeHrLé, De la coutume dans le droit canonique. Essai historique s'étendant des origines de l'Eglise au pontificat de Pie XI, Paris 1928; A. van Hove, Commentarium Lovaniense in codicem iuris canonici, vol. I, tom. III, De consuetudine, Mechliniae-Romae 1933, 3-237; P. Fedele, Il problema dell'animus communitatis nella dottrina canonistica della consuetudine, Milano 1937; G. MichIELs, Normae generales juris canonici, commentarius libri I codicis juris canonici, vol. II, tit. II, De consuetudine, Parisiis-Tornaci-Romae 1949, 1-220; J. ARIAS GómEZ, El consensus communitatis en la eficacia normativa de la costumbre, Pamplona 1966; M. FoRNASARI, La Consuetudine dalle collezioni canoniche gregoriane all'Ostienese, en Studi in onore di Marcello Magliocchetti, II, Roma 1975, 565-600; F. J. URRUTIA, Reflexiones acerca de la costumbre juridica en la Iglesia, en Investigationes theologico-canonicae, Roma 1978, 449-479; ID., De consuetudine canonica novi canones studio proponuntur, en Periodica de re morali, canonica, liturgica, LXX (1981), fasc. 1, 69-103; G. R. GIACOMAzzo, La consuetudine nella dottrina canonistica classica, Padova 1983; G. CомоттI, La consuetudine nel diritto canonico, Padova 1993; M. SANS GonZÁLEZ, La costumbre en la elaboración del Código de derecho canónico de 1917, en M. Tedeschi (a cura di), La consuetudine tra diritto vivente e diritto positivo, Soveria Mannelli 1998, 107-138; E. BAURA, La consuetudine, en Fondazione del diritto. Tipologia e interpretazione della norma canonica (Quaderni della Mendola, vol. 9), 81-104; G. Feliciani, La consuetudine nella codificazione del 1917, en Ius Ecclesiae, Rivista internazionale di Diritto Canonico, XIX 2 (2007), 333-346; P. BELlini, Tradizione e consuetudine nella esperienza del movimento cristiano principale, en Prassi e diritto. Valore e ruolo della consuetudine, Napoli 2008, 167-189.

${ }^{36}$ La costumbre tenía una disciplina específica en el CIC 1917 (cann. 25-20) y sigue teniéndola tanto en el CIC 1983 (cann. 23-28) como en el CCEO 1990 (cann. 15061509). 
der legislativo constituido, la conducta de la Iglesia no se ha limitado a la denuncia de las incoherencias entre tales leyes y los valores que constituyen el mensaje que Ella anuncia, sino que ha llegado en ocasiones a favorecer activamente su falta de receptividad.

Tal actitud no se manifiesta sólo ante las leyes que contradicen principios de la moral individual, que la Iglesia considera intangibles por más que sean los presuntos derechos individuales, ajenos a condicionamientos confesionales, la razón esgrimida por los poderes legislativos para justificar su promulgación; se afirma que tales derechos, en cuanto pertenecientes a la esfera exclusivamente privada, resultan extraños a la tutela del bien común o del orden público. La referida actitud de la Iglesia se ha manifestado también respecto a leyes directamente concernientes el concepto de orden público, como ocurrió con las de la tutela de la raza del Estado italiano, promulgadas en $1938^{37}$ y que, aunque llegaron a entrar en vigor, no fueron aceptadas por la mayoría de las personas en cuanto no correspondían al sentir general de la sociedad italiana ni a sus valores morales; contra las normas de la referida ley, la Iglesia desarrolló una labor muy meritoria poniendo a salvo enteras familias de judíos durante las persecuciones.

Aunque estos ejemplos demuestran el carácter sustancial que corresponde a la receptividad por parte de la comunidad de las leyes que se pretenden incluir en un ordenamiento jurídico, la impresión más frecuente es de signo opuesto. La orientación social y cultural surgida con la Revolución francesa sigue induciendo a considerar extrínseco al derecho el papel de la comunidad, como si su función

37 Regio Decreto-Legge 5 settembre 1938, n. 1390, Provvedimenti per la difesa della razza nella scuola; Regio Decreto-Legge 7 settembre 1938, n. 1381, Provvedimenti nei confronti degli Ebrei stranieri; Regio Decreto-Legge 15 settembre 1938, n. 1779, Integrazione e coordinamento in testo unico delle norme già emanate per la difesa della razza nella scuola italiana; Regio Decreto-Legge 17 novembre 1938, n. 1728, Provvedimenti per la difesa della razza italiana. Un comentario breve pero muy claro sobre las Leggi Razziali del Estado italiano se encuentra en P. GrossI, Pagina introduttiva (a sessant'anni dalle leggi razziali del 1938), estratto da Quaderni fiorentini per la storia del pensiero giuridico moderno, XXVII (1998), 1-9, donde el Autor afirma que dichas leyes eran «leggi formali dello Stato italiano, anche se strabuzzanti di un contenuto iniquo e ripugnante per la comune coscienza etica, uno di quei testi normativi durissimi per l'interprete-applicatore ma da tradurre da parte di costui in concretezza di vita "anche quando il contenuto... gli fa orrore» (come scriveva in modo disarmante Piero Calamandrei...). Valga questa "pagina introduttiva» da celebrazione infamante di un evento da non dimenticare. Certamente, prima di tutto, per l'imperdonabile traviamento cui fu sottoposto il nostro ordinamento positivo; ma valga anche da mònito per chi continua ad osannare a una legalità ad ogni costo, pur che sia, rigida ed astratta, prescindendo dalla necessaria verifica nella trama materna della società e della esperienza comune», 6. 
primordial se agotara en la elección libre del poder legislativo. En dicha idea pesa mucho el que, a pesar de las dinámicas típicas del proceso de globalización, la organización social siga estando aún fuertemente marcada por la estructura del Estado soberano; en ese contexto se sigue pensando que, respecto al poder legislativo, la comunidad carece de función intrínseca al ordenamiento jurídico.

Sin embargo, si se examinan los hechos desde una adecuada perspectiva histórica, se debe sostener lo contrario, pues en la era actual se entreven signos de una recuperación del derecho, en detrimento del monismo de la ley, y signos de un nuevo protagonismo de la comunidad, en detrimento del monismo del poder legislativo.

En realidad, el protagonismo de la comunidad y el valor de instrumentos jurídicos distintos de la ley, pueden considerarse rasgos constantes, aunque a veces haya resultado fatigoso evitar su sofocación completa, y no siempre hayan sido capaces de prevalecer ante la prepotencia de la ley y de la mera voluntad del poder legislativo. Piénsese, por ejemplo, en los derechos consuetudinarios que, a pesar de las dudas que con frecuencia surgen sobre su vigencia, se han mantenido incluso cuando regulan materias que, en época de codificaciones, parecieron reservarse exclusivamente al poder legislativo; es el caso del régimen matrimonial, respecto al cual las leyes pretenden ser reflejo de un sentir cultural que, a veces es más presunto que real, por lo que han supervivido fueros tradicionales que regulan las relaciones conyugales en sentido opuesto a las evoluciones legislativas sobre la materia ${ }^{38}$. Quiere ello decir que ni si quiera en el apogeo de la codificación, esto es, de los derechos oficiales nacidos del mito de la voluntas legislatoris, dejaron de existir completamente otros derechos plasmados en la conducta practica observada en un determinado tiempo y lugar por un grupo social concreto. La importancia de la experiencia práctica para el derecho es proporcional al protagonismo de la comunidad y resulta fundamental para todo ordenamiento jurídico.

${ }^{38}$ En una zona de Extremadura ha supervivido el Fuero de Baylío que regula el régimen económico matrimonial, al momento de la disolución de la sociedad conyugal, según un esquema de absoluta simetría entre los cónyuges. Esta supervivencia se ha verificado a pesar de que el artículo 1976 del Código Civil de 1889 derogase todo derecho consuetudinario y foral, excepto los mencionados expresamente, entre los que no se encuentra el Fuero de Baylío. Sobre las vicisitudes de este derecho foral cfr. M. Villalba Lava, El Fuero de Baylío como Derecho Foral de Extremadura, Badajoz 2009; puede considerarse discutible el objetivo que se propone el Autor, que aporta interesantes elementos pero propone como hipótesis que el legislador autonómico plasme en una ley los contenidos del fuero para fortalecer seguridad jurídica y su vigencia. 
La crisis del modernismo jurídico empieza a manifestarse en el s. $\mathrm{XX}$, en el que se acusan los síntomas más fuertes de lejanía entre el Estado y la sociedad. Algunos autores del momento como Santi Romano $^{39}$, Georges Ripert ${ }^{40}$ y, más recientemente, Paolo Grossi ${ }^{41}$, empezaron a advertir con vigor, desde diversas perspectivas, que el derecho proviene necesariamente de la base, esto es, de los destinatarios de las normas, pues el derecho es ordenamiento antes que norma, y en dicho ordenamiento la comunidad no puede no ser determinante.

«Más sociedad y menos Estado» puede considerarse el slogan que resume la crisis jurídica iniciada en el s. XX, cuya evolución, sin embargo, muestra que se trata de una crisis positiva, en la que lo que se abandona son los proyectos y esquemas jurídicos rígidamente concebidos y se da paso a una realidad compleja y plural, más desordenada, pero al mismo tiempo, terreno fértil para escribir el futuro en términos de pluralismo jurídico ${ }^{42}$ y de globalización jurídica ${ }^{43}$.

El pluralismo y la globalización que caracterizan la actual coyuntura jurídica vuelven a poner en el centro de la legitimación del

39 S. Romano, L'ordinamento giuridico, Firenze 1962; ID., Lo Stato moderno e la sua crisi. Saggi di diritto costituzionale, Milano 1969.

${ }^{40}$ G. RIPERT, Le déclin du droit - Etudes sur la législation contemporaine, Paris 1949, prólogo, VI: «quando il potere politico si manifesta in leggi che non sono più l'espressione del diritto, la società è in pericolo».

41 P. Grossi, Mitologie giuridiche della modernità, Milano 2005; ID., Il diritto tra potere e ordinamento, Napoli 2005; ID., Società, Diritto, Stato...cit.; ID., L'Europa del diritto, Bari 2007.

42 Son muchos los acontecimientos históricos que inducen a considerar el s. XX el momento en el que la sociedad inicia a quitar terreno al Estado. Baste citar dos de ellos, uno teórico y otro legislativo. El primero es la coferencia de Santi Romano en la inauguración del año académico 1909-1910 en la Università degli Studi di Pisa, con el título «Lo Stato moderno e la sua crisi»; se trata de un discurso iluminante en el que el jurista intuye el surgimiento del pluralismo jurídico y señala las fuerzas latentes que operararían en el Estado, aun sin confundirse con él (S. RomANo, Lo Stato moderno e la sua crisi...cit.. En la misma línea, cfr. P. Grossi, Santi Romano: un messaggio da ripensare nella odierna crisi delle fonti, en Rivista trimestrale di diritto e procedura civile, LX (2006), 377-395). El segundo es la Consitución de Weimar promulgada el 11 agosto 1919, y en la que el poder constituyente se propone ser voz de la sociedad en aquel determinado momento histórico; cfr. D. Donati, Corso di costituzioni straniere: la costituzione dell'Impero Germanico, Padova 1926; F. Poetzsch-Heffter, Handkommentar der Reichsverfassung vom 11 August 1919. Ein Handbuch für Verfassungsrecht und Verfassungspolitik, Berlin 1928; G. Anschütz, Die Verfassung des Deutschen Reiches vom 11. August 1919, Berlin 1933; C. MoRTati, Introduzione alla Costituzione di Weimar, Firenze 1946).

${ }^{43}$ Cfr. M. R. FerRaRESE, Le istituzioni della globalizzazione - Diritto e diritti nella società transnazionale, Bologna 2000. Téngase en cuenta que la llamada "globalización jurídica» de la era actual es un factor importante en la demolición del mito panlegalista de la era moderna. 
derecho su conexión real con la comunidad. Dicha conexión, sin embargo, no puede entenderse sólo según las categorías de la recepción o del rechazo social de la ley, si bien esas categorías permanecen como criterio firme. Se necesitan nuevas estrategias que alcancen la producción misma del derecho.

En efecto, la necesaria utilidad y correspondencia del ordenamiento jurídico a las exigencias y valores en los que se reconoce la comunidad de destinatarios, no consiente reducir el papel de la comunidad misma a la elección del poder legislativo. La historia del derecho, como muestran los ejemplos que hemos indicado, obliga a asegurar el espacio debido a la producción inmediata del mismo que pueda provenir de la base social. El instrumento tradicional al respecto ha sido la costumbre, que ha sido reconocida aun cuando era contra legem, si bien con distinto espacio y reglamentación el ordenamiento canónico o en el de los estados.

Aun con diversas formas de organización social, la naturaleza democrática de las sociedades permite, en el caso de los ordenamientos seculares, que los destinatarios de las leyes elijan los miembros del poder legislativo, incluido el de los foros supranacionales, tan importantes en una sociedad globalizada, tendente a la supresión de fronteras de tipo económico. La preponderancia de la economía pone de manifiesto la insuficiencia del papel electivo asignado a la comunidad, y no consiente el monopolio del derecho por parte del poder político. En la nueva era los protagonistas del poder económico han comprendido que el poder político no es capaz de crear y gestionar las relaciones jurídicas que se necesitan en el nuevo contexto globalizado.

Por esa razón, esos mismos protagonistas, desde la praxis que ellos han puesto en marcha en sus intercambios económicos, están elaborando nuevos institutos jurídicos, para cuya creación adecuada necesitan la aportación de una ciencia jurídica atenta a su vida y necesidades reales ${ }^{44}$, mientras se demuestra inútil el recurso a legis-

${ }_{44}$ El recurso a la ciencia jurídica para la adecuada formulación de la conciencia popular sobre el derecho se interpreta a veces como exigencia derivada del haberse retirado del pueblo la fuerza creadora del derecho; a esta idea del fundador de la escuela histórica del derecho, Savigny en su Sistema del derecho romano actual, citada por Vallet de Goytisolo, que gira en torno al concepto de "fuentes del derecho», este último autor, insistiendo en definir el derecho como quod bonum et aequum est, quod iustum est en acto y en concreto, contrapone el concepto alternativo de «elementos mediadores», para evitar la equiparación modernista entre derecho y ley; cfr. J. B. VALLET DE GOYTISOLO, ¿Fuentes formales del derecho o elementos mediadores entre la naturaleza de las cosas y los hechos jurídicos?, Madrid-Barcelona 2004, 12-14. 
ladores aislados en sus palacios de cristal, a los que, en la creación de leyes, parecen mover intereses ajenos a las necesidades reales de la sociedad, cuando no expresamente contrarios a la sensibilidad de la mayoría de sus miembros ${ }^{45}$.

Es un hecho notorio que, en el caso del ordenamiento eclesial, no hay elección del poder legislativo por parte de la comunidad; aun así, existen instrumentos jurídicos formales suficientemente idóneos para garantizar la citada función productiva del derecho que, también dentro de la Iglesia, resulta fundamental reconocer a la comunidad de fieles.

Aunque la costumbre, cual instrumento tradicional para la producción del derecho por parte de la comunidad, puede considerarse bastante devaluado en la actualidad eclesial ${ }^{46}$, no puede desconocerse el valor del que la costumbre, como institución formal, es portadora. Dicho valor es el sensus fidelium, del que son reflejo algunos de sus institutos peculiares como el Sínodo diocesano, el Consejo presbiteral, el Consejo parroquial. Por lo que se refiere a la actividad legislativa o normativa, son dignas de mención las distintas formas en las que el derecho de la Iglesia, además de promover nuevas formas de participación de los fieles, desde una nueva conciencia de su común corresponsabilidad ${ }^{47}$, reconoce la existencia de los derechos particulares o propios de ciertas entidades o formas de agrupación legítima (por ej. los reglamentos autónomos de movimientos, las reglas o constituciones de los Institutos de Vida Consagrada, los estatutos de las asociaciones de fieles, ...). No hay duda de que sobre éstos y sobre otros instrumentos jurídicos afines se necesita mayor creatividad para que el sensus fidelium se pueda expresar con mayor eficacia de la que consiente una aplicación demasiado reducida e inadecuada de estos mismos institutos ${ }^{48}$.

45 Sobre los nuevos retos que y el nuevo protagonismo de la ciencia jurídica en la era de la globalización cfr. P. Grossi, Europa y el derecho, traducción castellana de L. Giuliani, Barcelona 2008, 185-215.

46 Se habla de devaluación de la costumbre porque, desde el CIC 1917, su admisión en el ordenamiento canónico se produce exclusivamente a través de la voluntas legislatoris, única causa que legitima su valor jurídico como fuente del derecho (cfr. can. 25, Codex Iuris Canonici 1917; can. 23, Codex Iuris Canonici 1983; can. 1507, par. 4, Codex Canonum Ecclesiarum Orientalium).

47 Cfr. P. GHeRri (a cura di), Responsabilità ecclesiale, corresponsabilità e rappresentanza, Atti della Giornata Canonistica Interdisciplinare, Città del Vaticano 2010.

${ }^{48}$ Cfr. M. J. Arroba Conde, Diritto processuale canonico..., cit., 26-27. 
